\title{
The influence of shear bands on final structure and magnetic properties of $3 \%$ Si non-oriented silicon steel
}

\author{
Sebastião da Costa Paolinelli, ${ }^{\mathrm{a}, *}$, Marco Antônio da Cunha ${ }^{\mathrm{a}}$, André Barros Cota ${ }^{\mathrm{b}}$ \\ ${ }^{a}$ Research Department Arcelor Mittal Inox Brasil, Praça Primeiro de Maio, 9, Timóteo, MG-35180018, Brazil \\ ${ }^{\mathrm{b}}$ Physics Department, Redemat Universidade Federal de Ouro Preto, Campus Universitário, Ouro Preto, MG-3540000, Brazil
}

Available online 15 April 2008

\begin{abstract}
The presence of shear bands in the deformed material before final annealing is very important for Goss and Cube textures formation in silicon steel [S.C. Paolinelli, M.A. Cunha, J. Magn. Magn. Mater. 255 (2003) pp. 379. [1]; J.T. Park, J.A. Szpunar, Acta Mater., 51 (2003) 3037. [2]]. The increase of the hot-band grain size can increase the number of shear bands, which favor the nucleation of these orientations. In this work, the effect of the hot band grain size variation, promoted by varying the hot rolling finishing temperature, on final structure and magnetic properties was investigated for 3\% Si alloy. It was found that the increase of the hot-band grain size increases the occurrence of shear bands and promotes an increase of $\eta$ fiber fraction and a reduction of $\gamma$ fiber fraction, improving the magnetic induction. On the other hand, the final grain size is reduced when the hot-band grain size is larger than $190 \mu \mathrm{m}$, deteriorating the core loss values in spite of the texture benefits. The reduction of final grain size was explained by the increase of the number of nuclei at the beginning of the recrystallization caused by the increase of shear bands in the deformed material.
\end{abstract}

(C) 2008 Elsevier B.V. All rights reserved.

PACS: 61.25.Mv; 81.40.Rs; 81.40.Tf

Keywords: Silicon steel; Grain size; Shear bands; Texture; Magnetic properties

\section{Introduction}

The increase of the hot-band grain size is reported as a way to improve the final texture and increase magnetic induction and reduce core losses in non-oriented silicon steels [3]. In a recent paper [4] it was demonstrated, for $2 \%$ $\mathrm{Si}$ non-oriented steel, that the increase of the hot-band grain size improves the magnetic induction, but core loss is deteriorated when the hot-band grain size achieves larger values. In the present work, the behavior of non-oriented $3 \% \mathrm{Si}$ is analyzed taking into account microstructure heterogeneities, like shear bands. The variation of hotband grain size was obtained by varying the hot rolling finishing temperature.

\footnotetext{
*Corresponding author. Tel.: + 553138497593 ; fax: + 553138497501

E-mail address: sebastiao.paolinelli@arcelormittal.com.br (S.C. Paolinelli).
}

\section{Experimental}

Non-oriented silicon steel rougher bar samples with $25 \mathrm{~mm}$ thickness and chemical composition presented in Table 1 were reheated at $1150{ }^{\circ} \mathrm{C}$ and hot rolled to $2.3 \mathrm{~mm}$ in temperatures ranging from 920 to $1120^{\circ} \mathrm{C}$ in a lab reversible mill with heating between passes. They were cooled down to $550{ }^{\circ} \mathrm{C}$ with compressed air, kept in a furnace for $2 \mathrm{~h}$ at this temperature and were cooled down to room temperature in atmospheric air. The hot bands were annealed at $1030{ }^{\circ} \mathrm{C}$ and pickled in $20 \%$ hydrochloric acid solution, cold rolled to $0.50 \mathrm{~mm}$ and finally annealed at $1020{ }^{\circ} \mathrm{C}$ in $75 \% \mathrm{H}_{2}-25 \% \mathrm{~N}_{2}$ dry atmosphere. Final annealed samples were used for magnetic properties measurement and final structure observation. Annealed hot band samples with different grain sizes were cold rolled and annealed at low temperatures to observe the initial stages of the recrystallization. Grain size after each processing step was determinated by optical metallography and EBSD on the full area of the thickness section. 
Orientation distribution was obtained by X-ray analysis in the mid-thickness and micro-texture was analyzed by EBSD in the cross-section. Magnetic induction at $5000 \mathrm{~A} /$ $\mathrm{m}\left(B_{50}\right)$ and core losses at $1.5 \mathrm{~T}$ and $60 \mathrm{~Hz}\left(W_{1.5}\right)$ were measured in the rolling direction by using single-sheet tester of a Brockhaus MPG100D.

\section{Results and discussion}

Fig. 1 shows that the increase in hot-band grain size improves $B_{50}$ values and this is caused by the reduction in $\gamma$ fiber fraction and the increase in $\eta$ fiber fraction as shown in Fig. 2. $B_{50}$ is a property measured on the right of the "knee" of the magnetizing curve, where the changes on magnetic domains structure are made by rotation of the magnetic moments and is thus governed by the texture of the sample [5]. When the hot-band grain size increases, the texture is improved and the induction at $5000 \mathrm{~A} / \mathrm{m}$ increases, mainly when $\eta$ fiber fraction increases. It should be remembered that the measurements in Fig. 1 were made on the rolling direction.

For larger hot-band grain sizes, the core loss values increase. This increase can be explained by the reduction in final grain size when the hot-band grain size is over $190 \mu \mathrm{m}$, as shown in Fig. 3. For the larger hot-band grain sizes smaller final grain sizes were obtained. This behavior is similar to that found on $2 \% \mathrm{Si}$ steel [4].

$W_{1.5}$ is measured very close to the "knee" of the magnetizing curve and it is influenced not only by texture, but also by other microstructure parameters like grain size [5]. When the grain size decreases, hysteresis losses increases and when the grain size achieves lower values, its effect overcomes the benefits of texture improvement.

Table 1

Chemical composition (\%weight) of the experimental material

\begin{tabular}{lllllll}
\hline $\mathrm{C}$ & $\mathrm{Mn}$ & $\mathrm{Si}$ & $\mathrm{S}$ & $\mathrm{Al}$ & $\mathrm{Ti}$ & $\mathrm{N}$ \\
\hline 0.005 & 0.312 & 3.07 & 0.001 & 0.710 & 0.0027 & 0.002 \\
\hline
\end{tabular}

When the hot-band grain size increases, more microstructure heterogeneities like shear bands are observed in the deformed microstructure creating new nucleation sites on recrystallization. The grain boundaries area is reduced. Since the $\gamma$ fiber components are nucleated in grain boundaries, this component is reduced when the hot-band grain size increases [3]. Besides this effect, the $\alpha$ fiber fraction decreased when the hot-band grain size was increased by varying the hot rolling finishing temperature.

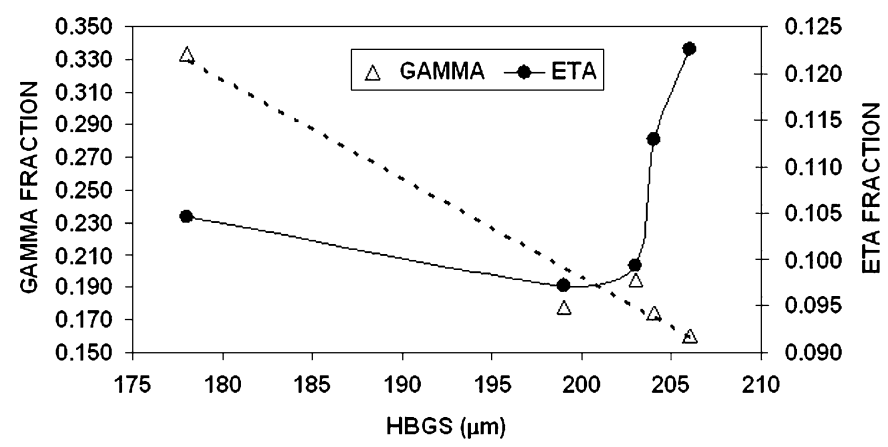

Fig. 2. Effect of the annealed hot-band grain size (HBGS) on $\gamma$ and $\eta$ fractions after final annealing.

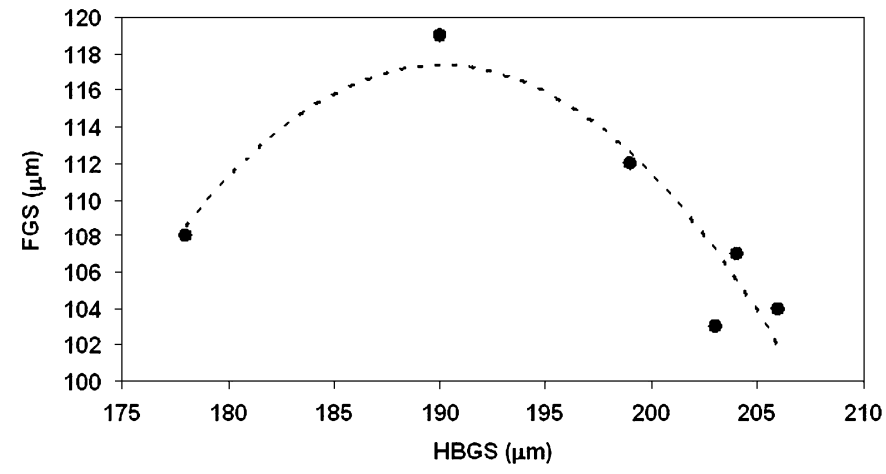

Fig. 3. Effect of the annealed hot-band grain size (HBGS) on final grain size (FGS).

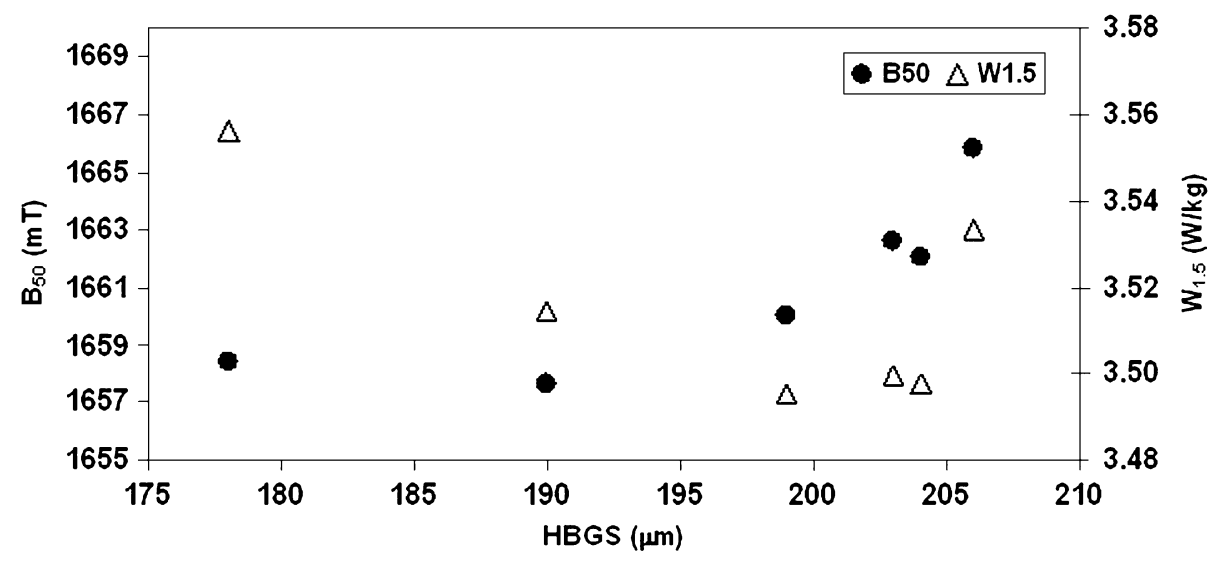

Fig. 1. Effect of the annealed hotband grain size (HBGS) on magnetic properties $B_{50}$ and $W_{1.5}$. 


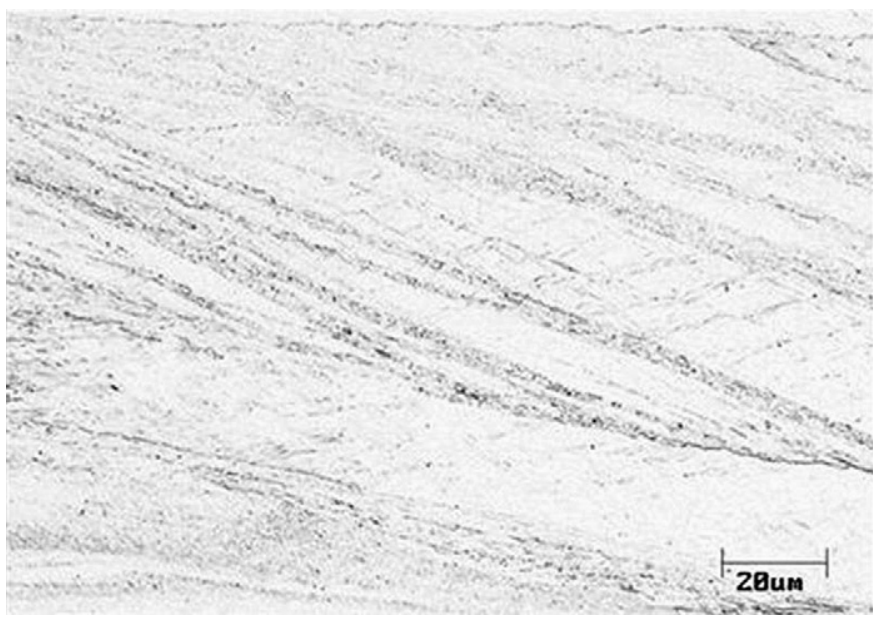

Fig. 4. Shear bands in the deformed sample with coarse hot-band grain size, annealed at $600^{\circ} \mathrm{C}$

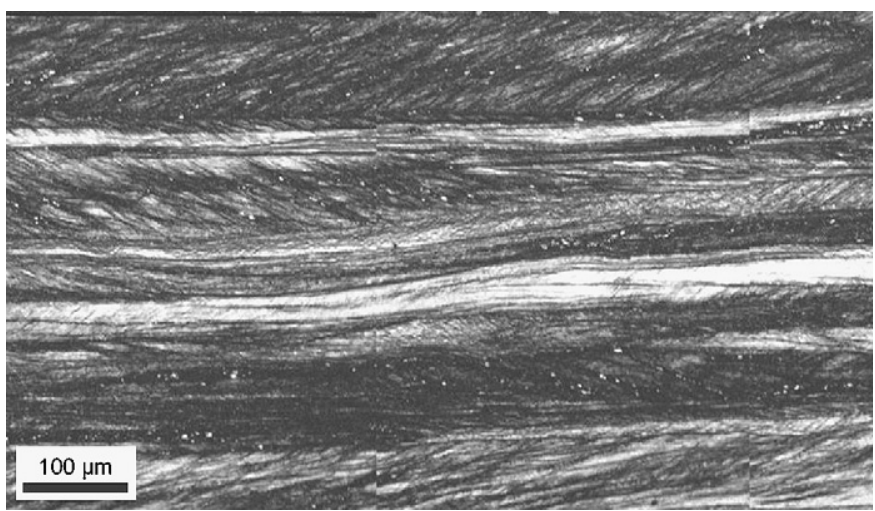

Fig. 5. Intensive shear banding in coarse hot-band structure cold rolled and the beginning of nucleation (white points) in these shear bands. Sample annealed at $620^{\circ} \mathrm{C}$.

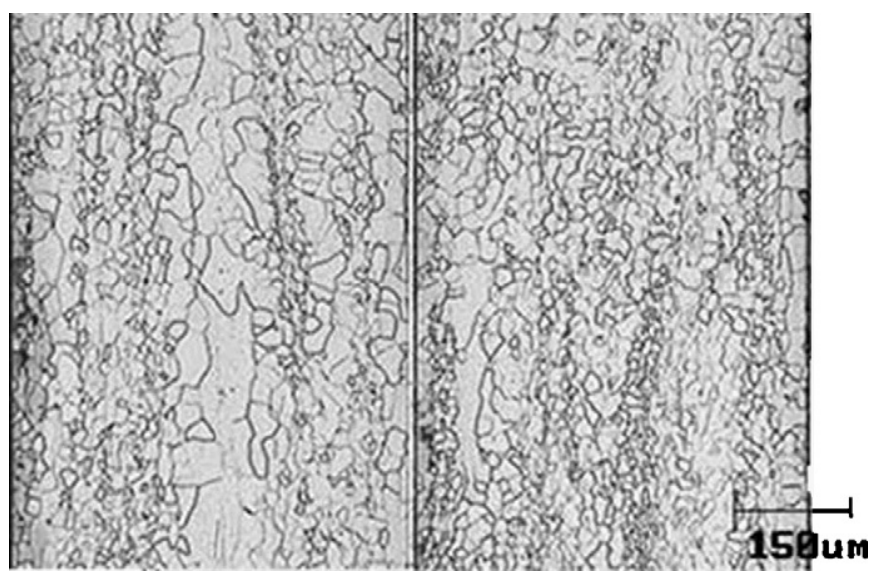

Fig. 6. Grain structure after primary recrystallization in the final annealing, for samples with small (left) and large (right) hot-band grain size.

This reduction in $\alpha$ fiber fraction in the hot band can also contribute to reduce $\gamma$ fiber fraction after final annealing, as reported in Refs. [6-7].
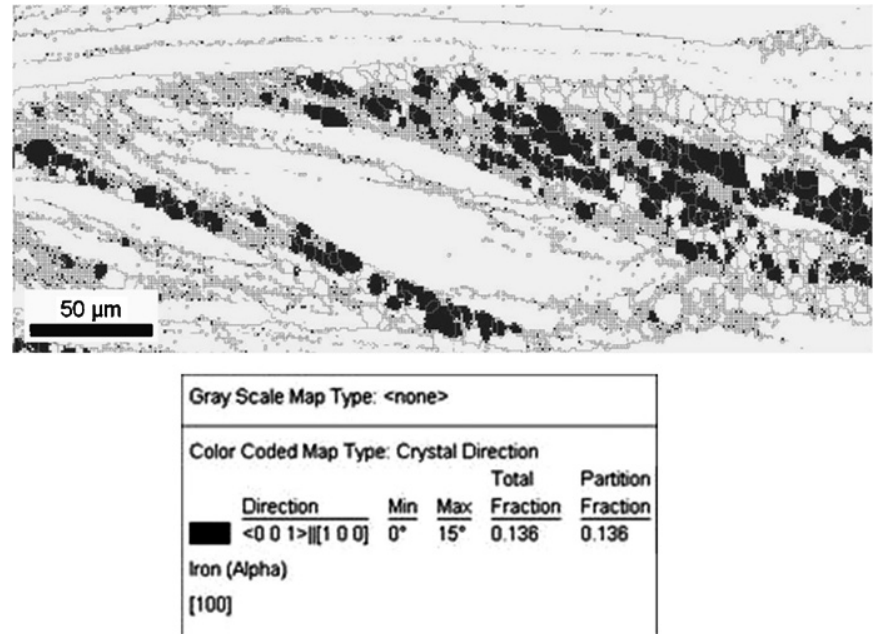

Fig. 7. Grains with orientations belonging to the $\eta$ fiber (grains with dark

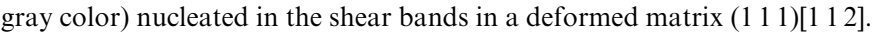

Fig. 4 shows intensive occurrence of shear bands in the sample with the largest hot-band grain size, particularly concentrated in grains with (1 1111$)\left[\begin{array}{lll}1 & 1 & 2\end{array}\right]$ orientation.

The shear bands are formed by very thin and elongated cells containing high dislocations density [8]. In the majority of the observations, the nucleation of the recrystallization began in the shear bands due to the large deformation energy accumulated. Fig. 5 shows the beginning of the recrystallization in a sample annealed at $620^{\circ} \mathrm{C}$. The nucleation begins in the shear bands and new grains follow the shear band direction, making normally $35^{\circ} \mathrm{C}$ with the rolling direction. Shear bands become additional sites for nucleation and in the material with initially coarser grain size, its intensive formation reduced the final grain size. Fig. 6 shows the structures at the end of the primary recrystallization for the smallest and for the largest hot band grain size of this experiment. The recrystallized microstructure corresponding to the largest hot band grain size presents smaller grain size and with the complete final annealing, after grain growth, this situation remains.

The contribution of shear bands to the texture can be seen in Fig. 7. Most of the grains nucleated on the shear bands belong to the $\eta$ fiber. These grains retain the disposition of the shear bands where they were nucleated up to the end of primary recrystallization. The final orientation will be a result of the competition between these grains and others nucleated with different orientations, during further grain growth. It was observed for this kind of material and the cold rolling process applied that $\eta$ fraction might reduce with the progress of grain growth [1].

\section{Conclusions}

When the hot-band grain size is increased, texture is improved by $\gamma$ fiber fraction reduction and $\eta$ fiber fraction increase. As a consequence, $B_{50}$ increases.

The strong occurrence of shear banding after cold rolling in the larger hot-band grain size samples provide additional 
number of sites of nucleation on recrystallization, reducing final grain size and contributing negatively for the core losses, in spite of the texture improvement. This behavior is very similar to that found for $2 \% \mathrm{Si}$ alloy.

\section{References}

[1] S.C. Paolinelli, M.A. Cunha, J. Magn. Magn. Mater. 255 (2003) 379-381.
[2] J.T. Park, J.A. Szpunar, Acta Mater. 51 (2003) 3037.

[3] H. Yashiki, T. Kaneko, The Sumitomo Search 44 (1990).

[4] S.C. Paolinelli, M.A. Cunha, A.B. Cota, Material Science Forum V (558-559) (2007) 787-792.

[5] M.F. Campos, F.J.G. Landgraf, N.B. Lima, A.P. Tschitschin, L.P. Me Brandão, In: Proceedings XXXIV Rolling Seminary ABM, Belo Horizonte, August, 1997, pp. 131-150.

[6] R.K. Ray, J.J. Jonas, R.E. Hook, Int. Mater. Rev. 39 (4) (1994) 129.

[7] M.R. Barnett, L. Kestens, ISIJ Int. 39 (9) (1999) 923.

[8] H. Paul, J.H. Driver, Bull. Pol. Acad. Sci. 54 (2) (2006) 209-220. 